\title{
Perinatal profile of ventricular overload markers in congenital diaphragmatic hernia
}

\author{
Maria João Baptista ${ }^{a, b}$, Cristina Nogueira-Silva ${ }^{a}$, José Carlos Areias ${ }^{b}$, \\ Jorge Correia-Pinto ${ }^{a, c, *}$
}

\author{
${ }^{\mathrm{a}}$ Life and Health Sciences Research Institute (ICVS), School of Health Sciences, University of Minho, Braga, Portugal \\ ${ }^{\mathrm{b}}$ Division of Pediatric Cardiology, Hospital S. João, Porto, Portugal \\ ${ }^{\mathrm{c}}$ Division of Pediatric Surgery, Hospital S. João, Porto, Portugal
}

Received 1 June 2007; revised 3 August 2007; accepted 11 August 2007

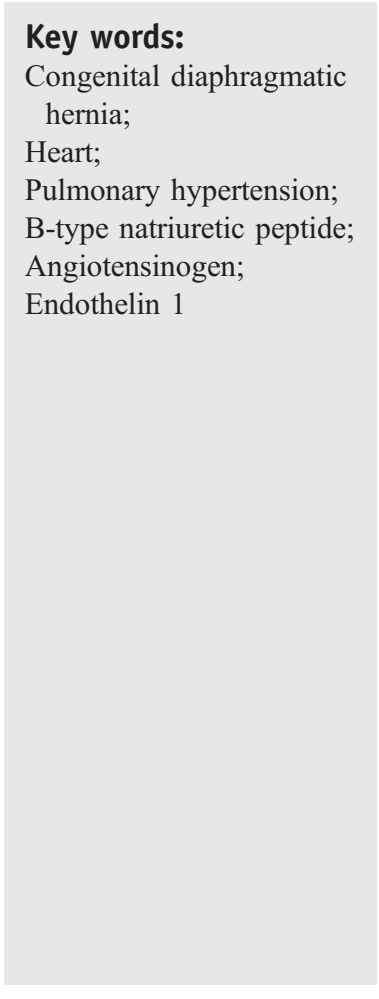

\begin{abstract}
Background: In congenital diaphragmatic hernia $(\mathrm{CDH})$, pulmonary hypertension increases right ventricle (RV) afterload, which could impair heart function and contribute to poor outcome for most affected infants. Nevertheless, the real significance of vascular pulmonary alterations in perinatal hemodynamics is largely unknown. It is defined that ventricular pressure overload induces increased myocardium gene expression of B-type natriuretic peptide (BNP) and components of the reninangiotensinogen and endothelin (ET)-1 systems. Our aim was to evaluate perinatal myocardium expression of these genes associated with ventricular pressure overload in a nitrofen-induced $\mathrm{CDH}$ rat model.

Methods: In the nitrofen-induced $\mathrm{CDH}$ rat model, fetuses from dated pregnant Sprague-Dawley rats at $15.5,17.5,19.5$ and 21.5 days postcoitum as well as newborn pups were assigned to 3 experimental groups: control, nitrofen (exposed to nitrofen, without $\mathrm{CDH}$ ), and $\mathrm{CDH}$ (exposed to nitrofen, with $\mathrm{CDH}$ ). Myocardial samples collected from the RV and left ventricle (LV) were processed for quantification of messenger RNA (mRNA) of BNP, angiotensinogen, and ET-1.

Results: The perinatal expression of BNP, angiotensinogen, and ET-1 mRNA in the RV and LV of the control group revealed daily changes. During gestation, the expression of BNP and angiotensinogen mRNA underwent significant oscillation compared with control in both nitrofen-exposed fetuses, although we cannot identify significant differences between the nitrofen and CDH groups. After birth, we found a significant increasing expression of all studied genes only in the RV of CDH pups.

Conclusions: Perinatal myocardial quantification of BNP, angiotensinogen, and ET-1 mRNA levels suggests that both nitrofen-exposed and control pups revealed prenatal variations of expression of the studied genes. Moreover, $\mathrm{CDH}$ is associated with significant molecular alterations only in the RV after birth.

(C) 2008 Elsevier Inc. All rights reserved.
\end{abstract}

* Corresponding author. Escola de Ciências da Saúde, Universidade do Minho, Campus de Gualtar, 4709-057 Braga, Portugal. Tel.: +351 253604 872; fax: +351 253604831 .

E-mail address: jcp@ecsaude.uminho.pt (J. Correia-Pinto).
Despite improvements in perinatal care, the mortality of fetuses and newborns with congenital diaphragmatic hernia $(\mathrm{CDH})$ remains exceedingly high [1]. This mortality seems to be related with severe pulmonary hypoplasia and pulmonary 
hypertension $(\mathrm{PH})$ [2]. Several authors suggested that, even in the absence of congenital heart disease, these infants could experience of some degree of cardiac underdevelopment $[3,4]$. In previous studies, we demonstrated in the experimental rat model of CDH the absence of left ventricle (LV) hypoplasia [5,6] or myocardium immaturity [7] in $\mathrm{CDH}$ fetuses. Nevertheless, the real significance of increased right ventricle (RV) afterload, because of neonatal $\mathrm{PH}$, in heart function is still unknown.

Another question that still persists in $\mathrm{CDH}$ is the true significance of $\mathrm{PH}$ in fetal hemodynamics and its consequences for the fetal heart. In infants with $\mathrm{CDH}$, pulmonary vascular modifications occur from early stages of prenatal development [8] and assume obvious significance after birth. Nevertheless, their meaning in fetal heart function is uncertain. Because fetal heart function is not easily assessed by ultrasonography, the evaluation of markers of ventricular overload in an experimental model of $\mathrm{CDH}$ might provide an appropriate alternative. Several biochemical and genetic markers have been suggested to evaluate ventricular load and function, both in animal models and humans, such as B-type natriuretic peptide (BNP), components of the renin-angiotensin system, and endothelin (ET)-1[9].

B-type natriuretic peptide is a hormone of predominantly ventricular origin produced and released in response to increased ventricular wall stress [10,11]. In recent years, it has emerged as a very sensitive biochemical marker for ventricular dysfunction in heart failure as well as in $\mathrm{PH}$, and its plasmatic level could be used to guide the response to therapy and to predict prognosis $[12,13]$. During normal fetal rat development, a very intense expression of BNP in the heart from 9.5 days postcoitum (dpc) was demonstrated, with major peaks of expression in stages that coincide with landmarks in heart development [14].

The components of the renin-angiotensin system and their roles in adult cardiac hypertrophy have been well documented $[15,16]$. In adult hearts, the increased hemodynamic load results in increased levels of angiotensin II that stimulates significant hypertrophy and remodeling of cardiac structure. Recent evidence from in vivo studies indicates that angiotensin II also acts as a growth factor and has a potential role in embryonic, fetal, and neonatal development of the heart [17-19]. In addition, the AT1 and AT2 angiotensin II receptor subtypes are present in the heart and are developmentally regulated [20].

Endothelin 1 is a potent vasoconstrictor peptide derived from endothelial cells that is also produced by cardiac myocytes [21]. Endothelin 1 induces myocardial cell hypertrophy and has potent positive inotropic and chronotropic effects on isolated heart muscle. These actions are mediated by the receptors for ET-1 (ETA and ETB receptors) on the cardiac myocytes [22]. The production of ET-1 in the heart is increased in pressure overload conditions, such as $\mathrm{PH}$ [23]. Several studies demonstrated that ET system has an important role in the developing heart, contributing to the formation of anatomical structures such as heart outflow tract and great vessels [24].

Interestingly, it was suggested in several previous studies that natriuretic peptides, angiotensin II, and ET-1 could play a significant role in the $\mathrm{PH}$ associated with $\mathrm{CDH}$ [25-29]. Moreover, in the rat model of $\mathrm{CDH}$, several authors reported significant modifications in heart expression of components from all these systems. Nevertheless, none of these studies assessed the messenger RNA (mRNA) expression of all these genes in both ventricles throughout gestation [30-32].

The aim of the current study was to evaluate, in the nitrofen-induced $\mathrm{CDH}$ rat model, $\mathrm{LV}$ and $\mathrm{RV}$ mRNA expression of BNP, angiotensinogen, and ET-1, genes previously defined as ventricular overload markers, in an attempt to evaluate the significance of $\mathrm{PH}$ in myocardium molecular adaptation during fetal development and transition after birth.

\section{Materials and methods}

The protocols used in this investigation were approved by the Institutional Animal Care and Use Committee and conform to the Guide for the Care and Use of Laboratory Animals published by the US National Institutes of Health Bethesda, MD, (publication no. 85-23, revised 1996).

\subsection{Animal model}

Pregnancy was obtained in 22 female Sprague-Dawley rats (225 g; Criffa, SA, Barcelona, Spain) after controlled overnight mating, and the finding of vaginal plug was counted as day 0 . At $9.5 \mathrm{dpc}$, pregnant rats were exposed to $100 \mathrm{mg}$ of nitrofen (2,4-dichlorophenyl-p-nitrophenylether) dissolved in $1 \mathrm{~mL}$ of olive oil administered by gavage or to an equal volume of olive oil alone [33]. Randomly, fetuses, treated with nitrofen or olive oil, were harvested by cesarean section at 15.5, 17.5, 19.5, and $21.5 \mathrm{dpc}$ (term gestation, 22 days), weighed on a precision balance (SBC 21; Scaltec Instruments, Heeligeesdadt, Germany), and killed by decapitation. To evaluate newborn rats, the gestation was continued in some pregnant rats until $22 \mathrm{dpc}$, and rats were allowed to deliver spontaneously. Newborns rats were harvested immediately after death or electively killed, by decapitation, at 6 hours after delivery. In this regard, it might be emphasized that all CDH pups died before our set point. After weighing pups, laparotomy was performed under binocular surgical microscopy (Wild M651.MS-D; Leica, Herbrugg, Switzerland) to inspect the diaphragm. Hearts were excised en bloc through median sternotomy. Myocardial samples were harvested from LV and RV free wall and snap-frozen at $-80^{\circ}$ for further molecular studies. Fetuses were assigned to the following 3 experimental groups: (i) control group - fetuses or pups exposed to olive oil alone, without $\mathrm{CDH}$; (ii) nitrofen group - fetuses or pups exposed 
to nitrofen without $\mathrm{CDH}$; and (iii) $\mathrm{CDH}$ group - fetuses or pups exposed to nitrofen with $\mathrm{CDH}$. Fetuses and pups with structural cardiac defects were excluded. Because it was not feasible to accurately identify a diaphragmatic defect at 15.5 dpc, only 2 groups were defined: control and nitrofen (exposed to nitrofen with or without $\mathrm{CDH}$ ).

\subsection{Molecular studies}

\subsubsection{Ribonucleic acid extraction and reverse transcription}

Total mRNA from LV and RV samples of 150 fetuses ( $\mathrm{n}=10$ each for control, nitrofen, and $\mathrm{CDH}$, in each studied time-point: $15.5 \mathrm{dpc}, 17.5 \mathrm{dpc}, 19.5 \mathrm{dpc}, 21.5 \mathrm{dpc}$, and newborn) was extracted using the RNeasy Mini Kit Protect (74712; Qiagen, Hilden, Germany). Quantification of total mRNA was done by spectrophotometry (BioPhotometer, Eppendorf, Germany), and the A260/A280 ratio was used to test protein and deoxyribonucleic contamination of the extracted product.

Reverse transcription was performed as previously described by Santos et al [34].

\subsubsection{Quantitative polymerase chain reaction}

Quantitative real-time polymerase chain reaction was performed as previously described by Santos et al [34].

Primer design was based on the available sequences in GenBank (NCBI-NLM-PubMed-Gene). All the primers are intron spanning (Table 1). For all the primer sets, standard amplification curves (ST curves) were made with randomly selected complementary DNA samples, setting $r=0.99$. The samples gene's expression was normalized for $\beta$-actin.

\subsection{Statistical analysis}

Results were presented as mean \pm SEM. Statistical analysis was performed using the SigmaStat 3.5 software (London, England). The different data sets of control, nitrofen, and $\mathrm{CDH}$ groups failed in the KolmogorovSmirnov test for normality. Therefore, statistical analysis was performed by the 1-way analysis of variance on ranks and the Dunn test for posttest analysis. Statistical significance was set at $P<.05$.

\section{Results}

The mRNA levels of BNP, angiotensinogen, and ET-1 (through gestation, in the RV and LV, in the control, nitrofen, and $\mathrm{CDH}$ groups) are presented in Figs. 1-3, respectively.

The BNP mRNA expression in the RV demonstrated in control group a significant decrease of around $19.5 \mathrm{dpc}$, followed by a peak increase at $21.5 \mathrm{dpc}$. After birth, its levels are similar to earlier studied stages of heart development. In comparison with the control group, we found significant differences both in nitrofen and $\mathrm{CDH}$ groups, characterized by a mirror-image pattern of expression, with inverse peak increase at $19.5 \mathrm{dpc}$ and a subsequent decrease at $21.5 \mathrm{dpc}$. After birth, the BNP mRNA expression in RV was similar in the nitrofen and control groups, but in the $\mathrm{CDH}$ group, we found a significant increase in its expression (5.5-fold) (Fig. 1).

The BNP mRNA expression in LV revealed a similar expression pattern in all study groups during fetal development. The control group had a significant decrease of around $19.5 \mathrm{dpc}$ followed by an increase at $21.5 \mathrm{dpc}$, although its magnitude was not as evident as occurred in the RV. Regarding the nitrofen and $\mathrm{CDH}$ groups, we also found a mirror-image pattern of expression. Nevertheless, after birth, the levels of BNP mRNA were similar to prior stages of heart development in the 3 groups (Fig. 1).

Concerning the expression of angiotensinogen mRNA in the RV, we observed a slight increase from $17.5 \mathrm{dpc}$ that peaked at $19.5 \mathrm{dpc}$, followed by a decrease to basal levels at $21.5 \mathrm{dpc}$. After birth, its levels remained constant. In the nitrofen and $\mathrm{CDH}$ groups, there was no significant variation in angiotensinogen mRNA expression through gestation. At birth, a significant rise occurred in the $\mathrm{CDH}$ group, compared with the control and nitrofen groups (Fig. 2).

Similar to the expression of BNP, in the control group, we found an LV angiotensinogen mRNA expression pattern similar to RV. Its expression rose from $17.5 \mathrm{dpc}$, peaked at $19.5 \mathrm{dpc}$, then slowly decreased until birth. Regarding the nitrofen and $\mathrm{CDH}$ groups, angiotensinogen mRNA levels in LV did not vary during gestation and after birth (Fig. 2).

In the control group, ET-1 mRNA level in RV showed a significant peak of expression at $19.5 \mathrm{dpc}$, followed by a constant level of expression that persisted even after birth. During fetal development, both the nitrofen and CDH groups

Table 1 Primers used for quantitative polymerase chain reaction

\begin{tabular}{|c|c|c|c|}
\hline Gene & Accession no. & Primer set & Product size (base pair) \\
\hline BNP & NM_031545 & 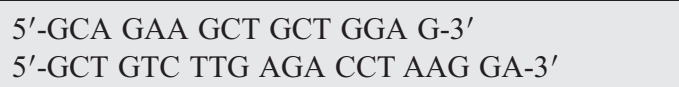 & 118 \\
\hline Angiotensinogen & NM_134432 & $\begin{array}{l}\text { 5'-GGATAAGTCCAGAGAGCGAG-3' } \\
\text { 5'-CAGACACCCCTGCTACAGTC-3' }\end{array}$ & 129 \\
\hline ET-1 & NM_012548 & $\begin{array}{l}\text { 5'-CAGAAACAGCTGTCTTGGGA-3' } \\
\text { 5'-GGAGGAGCAGGAGCAACG-3' }\end{array}$ & 116 \\
\hline$\beta$-actin & NM_031144 & 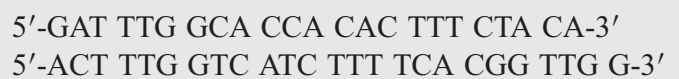 & 114 \\
\hline
\end{tabular}



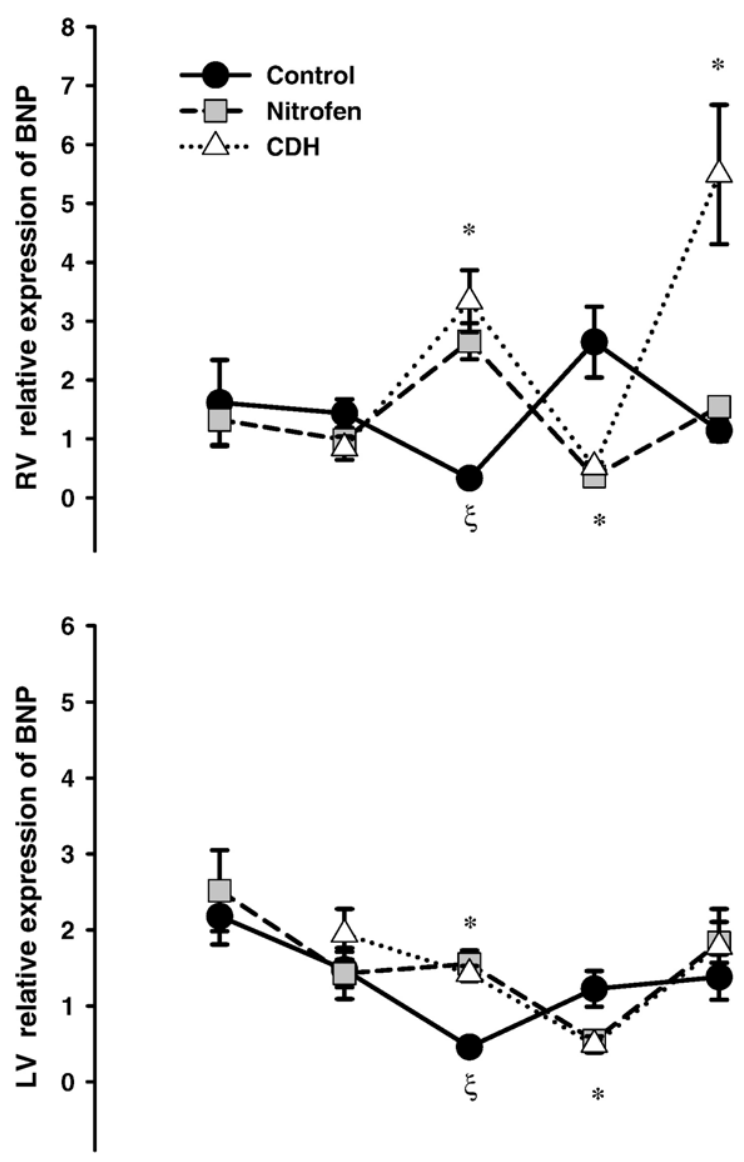

$15.5 \mathrm{dpc} 17.5 \mathrm{dpc} 19.5 \mathrm{dpc} 21.5 \mathrm{dpc}$ Newborn

Fig. 1 Expression of BNP mRNA from $15.5 \mathrm{dpc}$ to 6 hours of postnatal life in control, nitrofen, and $\mathrm{CDH}$ fetuses, both in RV (upper) and LV (bottom). ${ }^{*} P<.05$ vs control group; ${ }^{\xi} P<.05$ vs $16 \mathrm{dpc}$.

had exactly the same expression pattern, without any significant difference from control. However, after birth, whereas in the nitrofen group, we did not found any difference from the control group, the $\mathrm{CDH}$ group had a significant increase in ET-1 mRNA expression (Fig. 3).

Finally, the LV the expression of ET-1 mRNA showed a peak at $21.5 \mathrm{dpc}$ and returned to baseline levels after birth. In the nitrofen and $\mathrm{CDH}$ groups, we found the same pattern of expression of the gene, without any difference compared with the control group (Fig. 3).

To evaluate the relative expression changes of mRNA of studied genes in the LV and RV after birth, we used the RVto-LV mRNA ratio (Fig. 4). In the control group, mRNA of the 3 genes had similar relative expression in both ventricles. On the other hand, in the $\mathrm{CDH}$ group, we found a very significant increase in the RV-to-LV ratio expression patterns of BNP, angiotensinogen, and ET-1.

\section{Discussion}

In this study, we determined the cardiac expression of BNP, angiotensinogen, and ET-1 mRNA during perinatal development in normal and nitrofen-exposed rats. Cardiac expression of these genes showed temporal changes, suggesting a closely regulated developmental expression. Our results also showed late fetal cardiovascular disturbances in nitrofen-exposed fetuses. Moreover, it clearly illustrates that $\mathrm{CDH}$ pups, in early postnatal adaptation, experience severe RV molecular adaptation to pressure overload.

In our day, $\mathrm{CDH}$ remains a challenge in perinatology. The most severely affected babies have an extremely high mortality rate despite aggressive treatment. Persistent hypoxia because of pulmonary hypoplasia and hypertension is considered by several authors as the main problem in $\mathrm{CDH}$. Nevertheless, centers without extracorporeal membrane oxygenation did not significantly improve the outcome using techniques targeted to lung-dependent oxygenation, such as high-frequency ventilation or pulmonary vasodilator therapy. Although the real significance of $\mathrm{PH}$ is not completely defined in infants with $\mathrm{CDH}$, it is well known that severe $\mathrm{PH}$ is associated with increased mortality
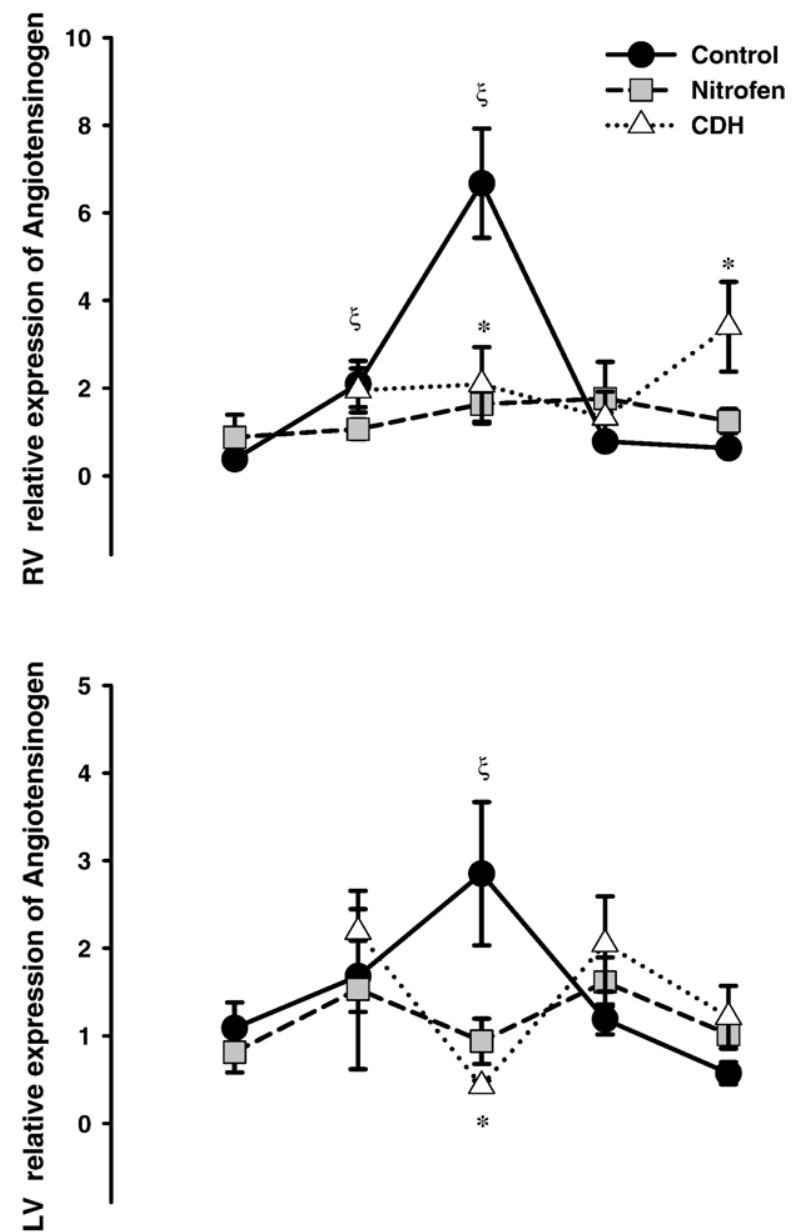

$15.5 \mathrm{dpc} \quad 17.5 \mathrm{dpc} \quad 19.5 \mathrm{dpc} 22 \mathrm{dpc}$ Newborn

Fig. 2 Expression of angiotensinogen mRNA from $15.5 \mathrm{dpc}$ to 6 hours of postnatal life in control, nitrofen, and CDH fetuses, both in RV (upper) and LV (bottom). ${ }^{*} P<.05$ vs control group; ${ }^{\xi} P<.05$ $16 \mathrm{dpc}$. 

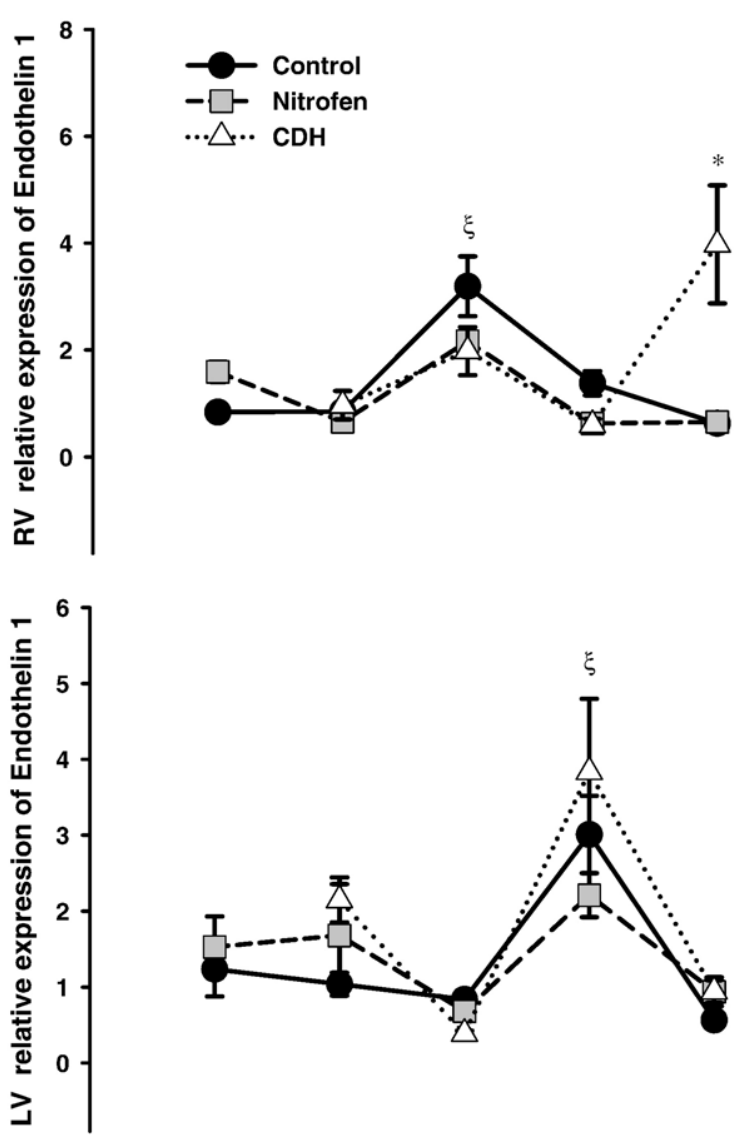

$15.5 \mathrm{dpc} 17.5 \mathrm{dpc} 19.5 \mathrm{dpc} 21.5 \mathrm{dpc}$ Newborn

Fig. 3 Expression of ET-1 mRNA from $15.5 \mathrm{dpc}$ to 6 hours of postnatal life in control, nitrofen, and $\mathrm{CDH}$ fetuses, both in $\mathrm{RV}$ (upper) and LV (bottom). ${ }^{*} P<.05$ vs control group; ${ }^{\xi} P<.05$ vs $16 \mathrm{dpc}$.

[35]. Pulmonary hypertension interferes with gas exchange as well as hampers myocardial performance, with additional compromise of pulmonary blood flow and tissue oxygenation [36].

From fetal to adult life, cardiopulmonary interaction plays a significant role in physiologic hemodynamics. Pathologic conditions affecting the lung or the heart could hamper this equilibrium. Although the pulmonary consequences of cardiac disease are well recognized, the influences of pulmonary changes on cardiac function are less well appreciated, particularly in fetuses. In late fetal life, several physiologic hemodynamic changes occur, such as initiation of ductus arteriosus closure and pulmonary vasodilatation, as well as increase in RV output to the pulmonary artery [37]. These modifications are promoted by many paracrine factors, among which systems such as natriuretic peptides, angiotensin, and ET-1 are supposed to play a role in different stages of heart development. Although significant alterations in these systems are well documented in pressure and volume cardiac overload in adults, the exact expression pattern of these genes in relation to fetal cardiac load was not previously defined. In our study, we demonstrated a

distinctive cardiac expression pattern of these genes during normal perinatal fetal rat development, presumably related to hemodynamic variations.

Endothelin 1 mRNA expression is different in the LV and $\mathrm{RV}$, probably because of different loads in the LV and RV. This gene has a peak expression at $19.5 \mathrm{dpc}$ in the RV, whereas in the LV, this occurs at $21.5 \mathrm{dpc}$. On the other hand, angiotensinogen and BNP have a very similar expression pattern in the RV and LV but a mirror expression compared with each other. We established that, in both ventricles, when BNP increases, angiotensinogen decreases. The opposed effect of natriuretic peptides and angiotensin in myocardium as well as in vessels is well known. Generally, BNP has potent inhibitory effects on the renin-angiotensin-aldosterone system [38], and in heart failure, activation of the reninangiotensin-aldosterone system is suppressed by BNP [39]. These systems might form an important regulatory complex of fetal vascular physiology and development. Hypothetically, dysregulation of these delicate control mechanisms could interfere with the cardiopulmonary hemodynamics and lead to disease.

Pulmonary vascular abnormalities in $\mathrm{CDH}$ have been well described from early stages of lung development. They consist of fewer pulmonary arteries per unit lung volume and peripheral muscularization of small arteries with medial and adventitial thickening [8]. Although the underlying mechanisms are not completely understood, these anomalies may cause abnormal vascular reactivity, and $\mathrm{CDH}$ lungs may become unable to adapt normally at birth [40]. The importance of abnormal vascular development as a determinant of survival in $\mathrm{CDH}$ has just recently been appreciated. Nonetheless, we are far from understanding the specific interplay of the factors regulating vascular tone in $\mathrm{CDH}$ as well as the significance of those anomalies during fetal heart and lung development.

In our work, we intended to define the fetal and neonatal expression pattern of 3 genes related to ventricular pressure

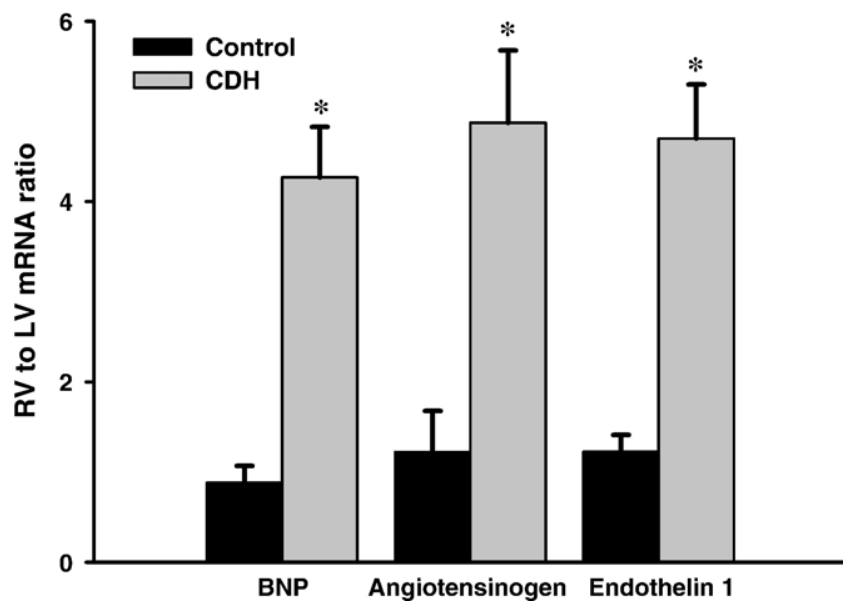

Fig. 4 Right ventricle-to-LV mRNA ratio of BNP, angiotensinogen, and ET-1 in control and $\mathrm{CDH}$ groups at 6 hours after birth. $* P<.05$ vs control group. 
load in the nitrofen rat model of $\mathrm{CDH}$. We demonstrated that during late fetal life, the nitrofen-exposed fetuses had significant variations in heart expression of mRNA BNP and angiotensinogen, evocative of cardiovascular disturbances. Remarkably, the mirror expression pattern of these 2 genes observed in control rat fetuses is preserved in nitrofen-exposed fetuses. Nevertheless, there are no alterations in ET-1 mRNA cardiac expression, and the variation reported in angiotensinogen and BNP genes occurred both in $\mathrm{CDH}$ and non-CDH nitrofen-exposed fetuses. These results suggest that the abnormalities observed are probably consequence of nitrofen action and not related to a hypothetical pulmonary vascular remodeling. We believe that, as occurs in several congenital malformations, $\mathrm{PH}$ in $\mathrm{CDH}$ is balanced during fetal life and should not have hemodynamic consequences or induce cardiac adaptation. In fact, pulmonary vascular remodeling, when present, should not cause elevated RV pressures in the fetus given the presence of the ductus arteriosus.

In infants with $\mathrm{CDH}$, intrauterine pulmonary hypoplasia and vascular remodeling may cause failure of pulmonary vascular resistance to fall at birth. This event implies an increased pressure overload to RV, with additional wall and endothelium stress, responsible for the initiation of cardiac adaptation. Several studies suggest that in $\mathrm{PH}$, the LV experiences both systolic and diastolic function adaptation because of bulging of the ventricular septum and diminished RV output [41]. In our study, the increased levels of all studied cardiac pressure overload markers in the RV of $\mathrm{CDH}$ pups after birth may indicate increased pulmonary vascular resistance in the $\mathrm{CDH}$ group. This response is specific for $\mathrm{RV}$, and in this model, we did not demonstrate any LV molecular adaptation to $\mathrm{PH}$.

In conclusion, perinatal myocardial quantification of BNP, ET-1, and angiotensinogen mRNA demonstrated that $\mathrm{CDH}$ is associated with significant molecular adaptation only in RV after birth. In fact, although nitrofen induced a hemodynamic imbalance in the expression of these genes, the major and novel observation from our work is the absence of cardiac impact of PH during late fetal life.

\section{References}

[1] Harrison MR, Keller RL, Hawgood SB, et al. A randomized trial of fetal endoscopic tracheal occlusion for severe congenital diaphragmatic hernia. N Engl J Med 2003;349:916-1924.

[2] Chinoy MR. Pulmonary hypoplasia and congenital diaphragmatic hernia: advances in the pathogenetics and regulation of lung development. J Surg Res 2002;106:209-23.

[3] Siebert JR, Haas JE, Beckwith JB. Left ventricular hypoplasia in congenital diaphragmatic hernia. J Pediatr Surg 1984;19:567-71.

[4] Crawford DC, Wright VM, Drake DP, et al. Fetal diaphragmatic hernia: the value of fetal echocardiography in the prediction of postnatal outcome. Br J Obstet Gynaecol 1989;96:705-10.

[5] Correia-Pinto J, Baptista MJ, Estevao-Costa J, et al. Heart-related indices in experimental diaphragmatic hernia. J Pediatr Surg 2000;35: 1449-52.
[6] Correia-Pinto J, Baptista MJ, Pedrosa C, et al. Fetal heart development in nitrofen-induced $\mathrm{CDH}$ rat model: the role of mechanical and nonmechanical factors. J Pediatr Surg 2003;38:1444-51.

[7] Baptista MJ, Recaman M, Melo-Rocha G, et al. Myocardium expression of connexin 43, SERCA2a, and myosin heavy chain isoforms are preserved in nitrofen-induced congenital diaphragmatic hernia rat model. J Pediatr Surg 2006;41:1532-8.

[8] Rottier R, Tibboel D. Fetal lung and diaphragm development in congenital diaphragmatic hernia. Semin Perinatol 2005;29:86-93.

[9] Aubert JD. Biochemical markers in the management of pulmonary hypertension. Swiss Med Wkly 2005;135:43-9.

[10] Baugman KL. B-type natriuretic peptide-a window to the heart. N Engl J Med 2002;93:1946-50.

[11] Bettencourt PM. Clinical usefulness of B-type natriuretic peptide measurement: present and future perspectives. Heart 2005;91: 1489-94.

[12] Bettencourt P, Azevedo A, Pimenta J, et al. N-terminal-pro-brain natriuretic peptide predicts outcome after hospital discharge in heart failure patients. Circulation 2004;110:2168-74.

[13] Nagaya N, Nishimi T, Uematsu M, et al. Plasma brain natriuretic peptide as a prognostic indicator in patients with primary pulmonary hypertension. Circulation 2000;102:865-70.

[14] Cameron VA, Aitken GD, Ellmers LJ, et al. The sites of gene expression of atrial, brain, and C-type natriuretic peptides in mouse fetal development: temporal changes in embryos and placenta. Endocrinology 1996;137:817-24.

[15] Baker KM, Booz GW, Dostal DE. Cardiac actions of angiotensin II: role of and intracardiac renin-angiotensin system. Annu Rev Physiol 1992;57:227-41.

[16] Lorell BH. Cardiac renin-angiotensin system: role in development of pressure overload hypertrophy. Can J Cardiol 1995;11(Suppl):7F-12F.

[17] Beinlich CJ, Baker KM, White GJ, et al. Control of growth in neonatal pig hearts. Mol Cell Biochem 1993;119:3-9.

[18] Aceto JF, Baker KM. [Sar1]angiotensin II receptor mediated stimulation of protein synthesis in chick heart cells. Am J Physiol 1990;258:H806-13.

[19] Price RL, Carver W, Simpson DG, et al. The effects of angiotensin II and specific angiotensin receptor blockers on embryonic cardiac development and looping patterns. Dev Biol 1997;192:572-84.

[20] Sechi LA, Sechi G, De Carli S, et al. Angiotensin receptors in the rat myocardium during pre- and postnatal development. Cardiologia 1993;38:471-6.

[21] Suzuki T, Kumazaki T, Mitsui Y. Endothelin-1 is produced and secreted by neonatal rat cardiac myocytes in vitro. Biochem Biophys Res Commun 1993;193:823-30.

[22] Miyauchi T, Masaki T. Pathophysiology of endothelin in cardiovascular system. Annu Rev Physiol 1999;61:391-415.

[23] Miyauchi T, Yorikane R, Sakai S, et al. Contribution of endogenous endothelin-1 to the progression of cardiopulmonary alterations in rats with monocrotaline-induced pulmonary hypertension. Circ Res 1993;73:887-97.

[24] Brand M, Kempf H, Paul M, et al. Expression of endothelins in human cardiogenesis. J Mol Med 2002;80:715-23.

[25] Shima H, Guarino N, Puri P. Antenatal dexamethasone improves atrial natriuretic peptide receptors in hypoplastic lung in nitrofeninduced diaphragmatic hernia in rats. Pediatr Surg Int 2000;16: 252-5.

[26] Bos AP, Sluiter W, Tenbrinck R, et al. Angiotensin-converting enzyme activity is increased in lungs of rats with pulmonary hypoplasia and congenital diaphragmatic hernia. Exp Lung Res 1995;21:41-50.

[27] de Lagausie P, de Buys-Roessingh A, Ferkdadji L, et al. Endothelin receptor expression in human lungs of newborns with congenital diaphragmatic hernia. J Pathol 2005;205:112-8.

[28] Okazaki T, Sharma HS, McCune SK, et al. Pulmonary vascular balance in congenital diaphragmatic hernia: enhanced endothelin-1 gene expression as a possible cause of pulmonary vasoconstriction. J Pediatr Surg 1998;33:81-4. 
[29] Rosenberg AA, Kennaugh J, Koppenhafer SL, et al. Elevated immunoreactive endothelin-1 levels in newborn infants with persistent pulmonary hypertension. J Pediatr 1993;123:109-14.

[30] Guarino N, Shima H, Puri P. Cardiac gene expression and synthesis of atrial natriuretic peptide in the nitrofen model of congenital diaphragmatic hernia in rats: effect of prenatal dexamethazone treatment. J Pediatr Surg 2001;36:1497-501.

[31] Teramoto H, Shinkai M, Puri P. Altered expression of angiotensin II receptor subtypes and transforming growth factor-beta in the heart of nitrofen-induced diaphragmatic hernia in rats. Pediatr Surg Int 2005; 21:148-52

[32] Guarino N, Puri P. Antenatal dexamethasone enhances endothelin-1 synthesis and gene expression in the heart in congenital diaphragmatic hernia in rats. J Pediatr Surg 2002;37:1563-7.

[33] Tenbrinck R, Tibboel D, Gaillard JL, et al. Experimentally induced congenital diaphragmatic hernia in rats. J Pediatr Surg 1990;25: 426-9.

[34] Santos M, Bastos P, Gonzaga S, et al. Ghrelin expression in human and rat fetal lungs and the effect of ghrelin administration in nitrofeninduced congenital diaphragmatic hernia. Pediatr Res 2006;59:531-7.
[35] Mohseni-Bod H, Bohn D. Pulmonary hypertension in congenital diaphragmatic hernia. Semin Pediatr Surg 2007;16:126-33.

[36] Henry GW. Noninvasive assessment of cardiac function and pulmonary hypertension in persistent pulmonary hypertension of the newborn. Clin Perinatol 1984;11:627-40.

[37] Rudolph AM. The fetal circulation and postnatal adaptation. In: Rudolph AM, editor. Congenital diseases of the heart: clinicalphysiological considerations. New York: Futura; 2001. p. 3-43.

[38] Burger AJ. A review of the renal and neurohormonal effects of B-type natriuretic peptide. Congest Heart Fail 2005;11:30-8.

[39] Takahashi N, Saito Y, Kuwahara K, et al. Angiotensin II-induced ventricular hypertrophy and extracellular signal-regulated kinase activation are suppressed in mice overexpressing brain natriuretic peptide in circulation. Hypertens Res 2003;26:847-53.

[40] Santos M, Moura RS, Gonzaga S, et al. Embryonic essential myosin light chain regulates fetal lung development in rats. Am J Respir Cell Mol Biol 2007;37:330-8.

[41] Louie EK, Lin SS, Reynertson SI, et al. Pressure and volume loading of the right ventricle have opposite effects on left ventricular ejection fraction. Circulation 1995;92:819-24. 